\title{
Trading System Upgrades and Short-Sale Bans: Uncoupling the Effects of Technology and Regulation
}

\author{
Bidisha Chakrabarty \\ Pamela C. Moulton \\ Roberto Pascual*
}

May 23, 2016

Journal of Empirical Finance, forthcoming

\begin{abstract}
* Bidisha Chakrabarty is at Saint Louis University (chakrab@slu.edu); Pamela C. Moulton is at Cornell University (pmoulton@cornell.edu); and Roberto Pascual is at University of the Balearic Islands (rpascual@uib.es). We thank an anonymous referee, Kevin Crotty, Rick Harris, Gbenga Ibikunle, Andriy Shkilko, and Fernando Zapatero for useful discussions, David Abad and Catalina Gaebler for data-related help, Bolsas y Mercados Españoles (BME) for providing data, Mikel Tapia, Jorge Yzaguirre (Head of Equities \& Derivatives at BME), and participants at the Annual Financial Market Liquidity Conference (Budapest, 2016), 14 $4^{\text {th }}$ INFINITY Conference on International Finance (Dublin, 2016), the Financial Management Association (FMA) Europe Meeting (Helsinki, 2016), the European Financial Management Association (EFMA) Meeting (Basel, 2016), the XXIV Finance Forum (Madrid, 2016), and seminar at ESADE Business School (Barcelona, 2016) for helpful comments. Roberto Pascual acknowledges the financial support of the Fundación BBVA and the Spanish DGICYT project ECO2013-4409-P. The opinions expressed in this paper are those of the authors exclusively.
\end{abstract}




\title{
Trading System Upgrades and Short-Sale Bans: Uncoupling the Effects of Technology and Regulation
}

\begin{abstract}
We examine the market quality effects of technology upgrades juxtaposed with short-sale bans. Between 2011 and 2013, the Spanish Stock Exchange introduced a smart trading platform (SIBE-Smart) and colocation to facilitate high-speed trading, and they also imposed two short-sale bans. We find that the SIBE-Smart introduction, which occurs between the two short-sale bans, leads to reduced market quality. The introduction of colocation, which occurs during the second short-sale ban, improves market liquidity although it does not attract additional high-speed trading. Our results highlight how the effects of latency-reducing infrastructure improvements depend on, and differ across, different regulatory regimes.
\end{abstract}

JEL Classification: G14, L10

Keywords: Technological upgrades, SIBE-Smart, colocation, short-sale ban, high-speed trading, equity market liquidity 


\section{Introduction}

Technological innovations in the last decade have facilitated speedier trading. Whether modern markets with fast traders (often called high-frequency traders, or HFT) provide a net benefit to investors is actively debated, with evidence pointing to both positive and negative effects of speed on market quality. ${ }^{1}$ The ambiguity about the impact of technological improvements is a special challenge to regulators, who want to ensure that any proposed regulation curbs the undesirable effects without undoing the benefits. Additionally, exchanges that adopt latency-reducing technologies must keep in mind that regulations may impact fast traders differently from other traders. Therefore, data-based evidence on the impact of regulation and technological improvements in modern markets should be of interest.

In this study we provide such evidence. Specifically, we examine whether technological enhancements improve market quality in the presence of trading restrictions. We exploit a unique setting that spans the interspersing of two short-sale bans with infrastructure upgrades and colocation on the Spanish Stock Exchange (SSE). Specifically, the SSE imposed a short-sale ban (SSB1) on August 11, 2011, which was lifted on February 15, 2012. Soon after the end of SSB1, on April 16, 2012, the SSE introduced a smart trading platform (SIBE-Smart) that upgraded the trading technology to increase efficiency and reduce connection latencies. On the heels of this upgrade came a second short-sale ban (SSB2), imposed on July 23, 2012. While SSB2 was in effect, the SSE announced that it would allow colocation for high-speed traders. This initiative was implemented on November 12, 2012. SSB2 ended about three months later, on January 31, 2013. The timeline below shows the chronology of these events.

\footnotetext{
${ }^{1}$ See Section 2 for related research.
} 


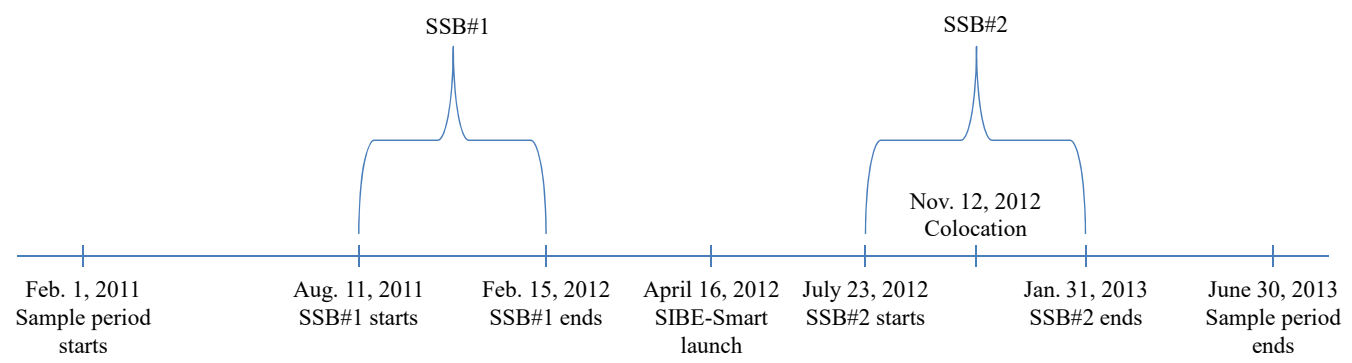

We conduct multiple event studies to investigate how various dimensions of market quality - liquidity, volatility, price efficiency, returns to liquidity provision, and adverse selection - are affected by the interaction of the technological upgrades with short-sale restrictions. Our event windows are designed to capture both the short-term and the longterm effects of the technology upgrades. The continuous electronic limit order book structure of the SSE is similar to many other equity markets around the world, so our results should be relevant to a broad set of other markets as well.

Short-sale bans are often used to limit precipitous price declines, although studies show that they have limited efficacy (Brogaard, Hendershott, and Riordan, 2016; Boehmer, Jones, and Zhang, 2013). But whether the effects of short-sale bans are alleviated or exacerbated by improvements in trading technology has not been explicitly tested. Our study addresses this issue by tracking market quality changes as the SSE adopts infrastructure upgrades juxtaposed with regulatory short-sale bans.

We use the timeline of events on the SSE to examine several questions. Do the expected positive effects of technological upgrades on market quality overcome the negative impact of short-sale bans? Do short-sale bans have a more profound effect on market quality in a low-latency environment? Or do regulatory restrictions outweigh the positive effects of technological upgrades, thereby exacerbating the negative effects of short-sale bans? We address these questions by analyzing short- and long-horizon 
windows surrounding the introduction of the smart trading platform (SIBE-Smart) and colocation juxtaposed with the two short-sale bans.

We document several novel findings. The SIBE-Smart trading platform introduction, which occurs after the first short-sale ban ends and before the second shortsale ban begins, is accompanied by an across-the-board deterioration of liquidity measures as well as reduced high-speed trading and quoting activity in the short run. In the long run some of the trading decline is reversed, but market quality does not improve. In our short-window analysis, the colocation event, which is announced during the second short-sale ban, is accompanied by a reduction in high-speed trading activity and liquidity. In the long-window analysis, we find that colocation significantly improves liquidity and reduces adverse selection costs, but it does not attract additional high-speed trading.

Comparing the periods before and after all of these events (SIBE-Smart, colocation, and the two short-sale bans), we find that liquidity worsens: Effective spreads increase, order book elasticity falls, and trading volume declines. In addition, return autocorrelation increases as does the price impact of trades. Finally, we find no overall increase in highspeed trading activity. Thus, when viewed over the entire sample period, the negative effects of the short-sale bans outweigh the positive effects of the technology upgrades, although when considered in isolation, colocation had a generally positive impact on market quality.

Taken together, these results indicate that the effects of latency-reducing infrastructure upgrades critically depend on the regulatory regimes within which they are implemented. Unlike previous studies that examine technological upgrades in markets without regulatory impediments, we do not find that such enhancements necessarily attract high-speed traders and improve market liquidity. For the SIBE-Smart introduction, 
which happens at a time when there is widespread expectation of an impending short-sale ban, there are no market quality improvements. In contrast, the introduction of colocation, which happens while a short-sale ban is in effect, improves market quality although it does not attract additional fast trading.

In addition to highlighting the important role of regulation in the relationship between technology upgrades and market quality, our results also underscore the importance of non-U.S. market settings in arriving at conclusions about the effect of regulations and trading infrastructure. There is an emerging body of literature which shows that many of the findings from U.S. markets do not generalize to other countries. We add to this international evidence on technological upgrades, regulations, and market outcomes.

The remainder of the paper is organized as follows. Section 2 presents a review of the related literature. Section 3 describes the institutional details of the SSE and discusses the timeline of events spanned by our sample period. Section 4 discusses the sample selection and market quality metrics. Section 5 provides methodological details. Section 6 presents our results. Section 7 presents robustness checks, and Section 8 concludes. In the Appendix, we list our sample stocks and present additional results.

\section{Trading technology and short-sale ban background}

\subsection{Technological upgrades, fast trading, and market quality}

As technological advances replace old trading systems with newer and faster ones, regulators face the challenge of adapting rulemaking to the new realities of modern markets. In March 2014, the SEC released a comprehensive review of the U.S. equity market structure, with half of the study devoted to reviewing the existing evidence on high-speed trading. Around the same time (April 15, 2014), European regulators imposed 
tough regulations on high-frequency traders in the E.U. These rules include limits to keep price increments for low-priced stocks from becoming too small, tests of trading algorithms, and a requirement that market makers provide liquidity for a minimum number of hours each day. ${ }^{2}$

Research shows that technological enhancements that facilitate fast trading have mixed market quality effects. ${ }^{3}$ Hendershott, Jones, and Menkveld (2011) find that the introduction of Autoquote, which facilitates algorithmic trading, improves market quality by reducing spreads and adverse selection and improving the informativeness of quotes. Brogaard, Hagstromer, Norden, and Riordan (2015) find that although colocation provides informational advantages to HFT, overall market quality is improved after the introduction of colocation. Malinova, Park, and Riordan (2016) use data from the Toronto Stock Exchange to examine how regulation affects market quality by testing the impact of a tax on HFT. They find that quoted and effective spreads increase and revenues to liquidity supply decline, indicating that regulation that reduces fast trading may harm some dimensions of market quality. Brogaard, Hendershott, Hunt, and Ysusi (2014) do not find any evidence of increased institutional trading costs as a result of increased HFT activity facilitated by technology upgrades on the London Stock Exchange. Brogaard et al. (2015) study a colocation upgrade at NASDAQ OMX Stockholm that improves connectivity of high-speed traders. They find that liquidity increases because highfrequency market makers use the enhanced speed to reduce their exposure to adverse selection and to better manage inventory.

\footnotetext{
${ }^{2}$ http://www.europarl.europa.eu/news/en/news-room/content/20140411IPR43438/html/MEPs-vote-laws-to-regulatefinancial-markets-and-curb-high-frequency-trading

${ }^{3}$ See also the review provided by the SEC at

http://www.sec.gov/marketstructure/research/hft lit review march 2014.pdf (last access, July 13, 2016).
} 
Other studies document negative market quality effects of trading technology that facilitates fast traders. For example, Boehmer, Fong, and Wu (2015) find that fast traders degrade the market quality of small stocks in a study that examines the introduction of colocation in multiple markets around the world. Thus, whether technologies that facilitate high-speed trading provide net benefits in terms of improved liquidity and increased price efficiency is still open for debate,

\subsection{Short-sale bans and market quality}

Researchers agree that short sellers perform a useful function by incorporating fundamental information into prices. Or, as Boehmer, Jones, and Zhang (2013) put it: "For the most part, financial economists consider short sellers to be the good guys." Karpoff and Lou (2010) find that short sellers detect financial fraud in firms about 19 months before the misrepresentation is publicly revealed. In a similar vein, Desai, Krishnamurthy, and Venkataraman (2006) show that short sellers pay attention to firms' accounting numbers and can anticipate earnings restatements several months in advance. Given the information-gathering role that short sellers perform, it is no surprise that market quality declines when regulatory bans are imposed on short selling.

The 2008 recession and the European debt crisis in 2010-2011 saw several countries around the world impose ad hoc short-sale bans to try to stem price declines. In the U.S., the SEC issued an emergency order restricting naked short selling in July 2008, and followed that up with an outright short-sale ban in September. Analyzing the effects of this ban, Boehmer, Jones, and Zhang (2013) find that market quality worsens because many algorithmic traders cannot act as informal market makers. With less competition, formal market makers can now charge greater rents for liquidity provision. Battalio, Mehran, and Schultz (2012) study a similar decline is U.S. stock markets following the 
S\&P downgrade of the U.S. in 2011. They find that short sellers do not amplify stock price declines during times of market downturn.

The 2011 debt crisis saw the imposition of short-sale bans in Greece, Turkey, Belgium, France, Italy, and Spain. Similar to the U.S. experience, the evidence points to dubious efficacy of short-sale bans. Beber and Pagano (2013) study the effects of the 2008 stock price decline in 30 countries around the world. Comparing countries that did not impose a blanket ban on short selling for all stocks to those that did, they conclude that the effect of such bans on stock prices is neutral at best. Bris, Goetzman, and Zhu (2007) analyze cross-sectional and time-series information from 46 countries and show that prices are more efficient in countries that allow and practice short sales.

\section{Institutional details of the Spanish Stock Exchange and timeline of events}

The SSE has four trading platforms: Madrid, Barcelona, Bilbao, and Valencia. Trading is linked through the electronic Spanish Stock Market Interconnection System (SIBE), which handles more than $90 \%$ of transactions. The benchmark index is the IBEX35, a capitalization-weighted index comprising the 35 most liquid Spanish stocks traded in the continuous market. Trading on SIBE is conducted from 9:00 a.m. to 5:30 p.m., with automated opening and closing call auctions from 8:30 to 9:00 a.m. and 5:30 to 5:35 p.m., respectively. During the rest of the trading day the SSE operates as a continuous electronic limit order book. Thus, the SSE trading protocol is similar to many other equity markets around the world, including the NASDAQ (U.S.), Xetra (Germany), the Australian Stock Exchange, and the National Stock Exchange of India.

After the steep declines in equity markets across Europe (including Spain) in 2008, the IBEX-35 recovered remarkably to become Europe's best performer in 2009. But 2010 was a down year due to increased country risk and the weakness of the European financial 
sector. The index fell $17.43 \%$ after fluctuating in a very wide range of $35 \%$ between its peak and low; however, the drop in share prices did not erode the levels of activity and 2010 set a new record in SSE trading volume.

In response to the European market declines, in mid-2011 ESMA issued a statement that all negative bets on financial stocks — in other words, short sales - would be curtailed in France, Belgium, Italy, and Spain effective August 11. This ban lasted until February 15, 2012, when the Spanish securities regulator, the Comisión Nacional del Mercado de Valores (CNMV), announced that the prohibition on short sales of Spanish shares under the EU Short Selling Regulation (EU236/2012) was no longer in effect after February 15. However, as many market commentators had anticipated, once the ban was removed, prices declined precipitously, leading the CNMV to announce that "European shares have been hit with extreme volatility that might cause the disorderly functioning of financial markets." In response, a second ban was introduced (affecting all stocks) on July 23, 2012; it was subsequently lifted on January 31, 2013.

During this time the SSE also introduced major technology upgrades to integrate better with the bigger European exchanges and facilitate high-speed trading. Two major technology changes that facilitated faster trading were an upgrade of the SIBE-Smart platform and the introduction of colocation. Recognizing that HFT in securities markets is extensive and a natural progression in the wake of the widespread introduction of electronic markets and the increasing use of computerized trading systems, the SSE committed to developing their trading infrastructure and communications technology. As part of that effort, they rolled out the SIBE-Smart platform on April 16, 2012, to better adapt SSE's systems to new demands in terms of transaction speed and volume in the market. Following up on this technological enhancement, the SSE began offering colocation capabilities at its Data Processing Center in Madrid on November 12, 2012, 
enabling trading firms to install their own trading servers in close proximity to the exchange's trading engines and real-time price distribution systems. SSE officials stated that these efforts were expected to reduce latency, increase capacity for traders, and directly facilitate HFT. ${ }^{4}$ Fortunately for our study, there were no significant changes in the SSE's fee structure during our sample period (Chesini, 2012).

\section{Sample selection and market quality measures}

Our sample comprises the SSE-listed IBEX-35 constituents from February 2011 to June 2013. Due to index additions and deletions, our final sample includes 36 stocks that are index constituents throughout our sample period (see the Appendix for a list of the sample stocks). Our market data come from the SSE's trade and limit order book (LOB) files. Trade files report all trades time-stamped up to the hundredth of a second before April 16, 2012 (launch of the SIBE-Smart) and milliseconds afterwards. For each trade, the record includes the price and size.

The order book files contain snapshots of the five best ask and bid quotes of the LOB taken each time the LOB changes as a result of trades, order submissions, cancelations, or modifications. For each LOB level we have the quote record, the number of orders at that quote, and the displayed depth. The SSE allows iceberg orders, but the quote files do not provide information on hidden volume (see Pardo and Pascual, 2012). ${ }^{5}$ Relatively large buy (sell) trades are allowed to walk up (down) the book. Thus, the trade price is actually the marginal price, that is, the price at which the last share of the trade was transferred. The minimum trade size on the SSE is one share.

\footnotetext{
${ }^{4}$ See announcement at http://www.world-exchanges.org/news-views/bme-successfully-upgrades-spanishstock-exchange $\% \mathrm{E} 2 \% 80 \% 99$ s-trading-platform.

${ }^{5}$ We verify that there are no changes in detected hidden orders around the events we study; see robustness checks in Section 7.
} 
Both the trade and the LOB files contain a sequence code, allowing for a perfect match between trade and quotes. Since there are no price improvements (i.e., trades inside the spread) and every trade consumes liquidity either at the displayed ask or bid quote, it is straightforward to assign trade direction (i.e., buyer- or seller-initiated). A trade is classified as buyer-initiated (seller-initiated) if it consumes liquidity at the offer (demand) side of the LOB, which is commonly called the quote rule.

We filter out records from the opening, closing, and intraday short-lived call auctions in each file and use only quotes and trades from the continuous session. We also filter out prearranged trades.

\subsection{Liquidity and market activity measures}

We calculate a variety of proxies for liquidity and market activity. The effective spread (ESpr) is two times the difference between the trade $t$ price $\left(p_{t}\right)$ and the prevailing quote midpoint before trade $t\left(q_{t}\right)$, multiplied by the trade direction ( 1 for buyer initiated; -1 for seller-initiated). In computing the daily measure, we weight each observation by trade size. The accumulated displayed LOB euro-depth (Depth) is the euro-value of the displayed depth at the five best levels of the LOB averaged weighting by time. It occasionally happens that spreads and depth give opposite signals on liquidity, such as effective spreads widening while depth increases. To summarize the net change in liquidity in such situations, we also calculate the two-dimensional liquidity measure LOB elasticity. We follow Näes and Skjeltorp (2006) and compute the elasticity of the bid side LOBElast $t_{i j}^{b}$, and the ask side LOBElast $t_{i j}^{a}$ and take the time-weighted average of the two to obtain the daily LOB elasticity (LOBElast). ESpr is an inverse measure of liquidity while Depth and LOBElast are direct measures of liquidity. For market activity, we use 
the following three daily measures: Vol is the daily volume in shares, Trades is the daily number of trades, and Vol€ is the daily volume in euros.

\subsection{Volatility and price efficiency measures}

Our metric for daily stock price volatility is the realized volatility (RVolat), which is computed as the daily standard deviation of one-minute trade price continuouslycompounded returns.

We compute two daily proxies for price efficiency: the first-order autocorrelation of one-minute trade price continuously-compound returns $\left(\right.$ Corr $\left._{i d}\right)$ and the pricing error standard deviation ( $\operatorname{PrErr}_{\text {id }}$ ) estimated using Hasbrouck (1993). For each stock-day, we

estimate a bivariate Vector Autoregressive (VAR) model for $\left\{r_{t}, x_{t}^{s}\right\}$, where $r_{t}$ is the return of trade $t$ and $x_{t}^{s}$ is the signed trade size. We choose the optimal VAR lag using the Akaike Information Criterion (AIC), and the model is estimated using OLS. PrErr ${ }_{i d}$ is obtained from the coefficients of the Vector Moving Average (VMA) representation of the VAR model and the variance-covariance matrix of the residuals.

\subsection{Realized spread and price impact}

We estimate the revenue to liquidity providers using the realized spread (RSpr) and measure gross losses to liquidity demanders due to adverse selection using the price impact (PrImp) of a trade, as in Huang and Stoll (1996) and Hendershott, Jones, and Menkveld (2011). The price impact of trade $t$ is two times the difference between the quote midpoint prevailing $\Delta$ seconds after the focal trade (i.e., $t+\Delta$ ) and the midpoint prevailing right before trade $t$, multiplied by the trade direction. The daily average PrImp is weighted by trade size. The realized spread for trade $t$ is computed as the difference 
between the effective spread and the price impact. Results are reported for $\Delta=$ five seconds; in robustness checks, we fnd that inference is unchanged using 15,30 , and 60 seconds.

\subsection{High-speed trading activity measures}

The SSE dataset does not contain information about trader identities, nor does it indicate when orders or trades come from the same trader, so we calculate proxies for high-speed trading based on message traffic, quoting intensity, and cancellations (as in, e.g., Hendershott, Jones, and Menkveld, 2011; Conrad, Wahal, and Xiang, 2015; Aiken, Aspris, Foley, and Harris, 2015). ${ }^{6}$ Our proxies are message traffic per volume in shares (MTVSh), message traffic to trades (MTTrd), cancellations to share volume (CANVSh), cancellations to trades (CANTrd), quote intensity to share volume (QIntVSh), and quote intensity to trades (QIntTrd). Message traffic is the number of LOB updates per day, which is equivalent to summing all order submissions, cancellations, and revisions. Quote intensity is defined as changes in either price or share depth at the best quotes of the LOB. We identify cancellations from LOB updates as follows. We first match the trade and LOB files using the internal sequence indicator to account for depth reductions due to order executions. The remaining LOB updates are classified into: (a) limit order submissions, when depth increases at any of the five levels from the previous quote; (b) limit order revisions, when depth increases at some levels and decreases at others, and (c) cancellations, when depth decreases at any of the five levels from the previous quote.

\section{Methodology}

\footnotetext{
${ }^{6}$ Note that our proxies do not capture the number of high-speed traders, but rather the amount of highspeed trading in aggregate.
} 
We estimate each event's impact on our variables of interest by running pooled regressions. For the two technological upgrades (SIBE-Smart and colocation), we conduct our analyses over both a short window (five days before and after each event) and a long window (several weeks before and after the event of interest) because changes in trader behavior may differ in the short term versus the long term. We run long-window analyses for all of the events during our sample period.

To aggregate high-frequency data for the short-window analyses, we face a tradeoff between the precision of estimates and the number of observations. We report findings with a 30-minute resolution for all metrics except PrErr, for which we keep the 60-minute resolution. Our results are similar if we use the 60-minute resolution for all metrics instead. ${ }^{7}$ For the long-window analyses we aggregate data at daily intervals. In all regressions standard errors are double-clustered by stock and date using the procedure outlined in Thompson (2011).

The short-window regressions take the following form:

$$
Y_{i t}=\alpha+\beta_{E} E_{i t}+\sum_{i=2}^{17} \beta_{I} I_{i t}+\varepsilon_{i t}
$$

where $Y_{i t}$ is one of the intraday market quality metrics defined in Section $4 ; E_{i t}$ is an indicator for the event under consideration (SIBE-Smart introduction or colocation) that equals one for the post-event period and zero for the pre-event period, and $I_{i t}$ are a set of 16 dummies for each 30-min interval (we omit the first half hour dummy). The coefficient

\footnotetext{
${ }^{7}$ Pricing errors cannot be computed with a 30 -minute resolution. With a 60 -minute resolution, $92 \%(100 \%)$ of the stocks have an average number of trades per interval greater than $100(50)$ around the introduction of the SIBE-Smart. During the second short-sale ban, this percentage falls to $39 \%(78 \%)$ around the introduction of colocation.
} 
of interest is $\beta_{E}$, which captures the difference in each dependent variable between the pre- and post-event period.

Our model for the long-window regressions includes controls for potential lowfrequency confounds and takes the following form:

$$
Y_{i d}=\alpha+\beta_{E} E_{i d}+\beta_{V} \text { Volat }_{-1}+\beta_{X} \text { XRet }_{-1}+\beta_{D} \Delta \text { Yield }_{-1}+\beta_{R} \Delta \text { SRisk }_{-1}+\sum_{s=2}^{6} \beta_{s} \text { ISect }_{\text {id }}+\varepsilon_{\text {id }},
$$

where $Y_{\text {id }}$ is one of the daily market quality metrics defined in Section 4; $E_{i d}$ is an indicator for the event under consideration that equals one for the post-event period and zero for the pre-event period; XRet is the IBEX-35 return; Volat is the IBEX-35 volatility, computed as the daily high/low; $\triangle$ GBYield is the first difference of the long-term Spanish Government Debt yield; $\Delta$ SovRisk is the first difference of the sovereign risk of Spain, computed as the difference between the government debt yield of Spain and Germany; and ISect are industry sector dummies from the BME's six industry sectors. We control for market-wide volatility because Cáceres, Moreno, and Rodriguez (2014) show that the short-sale bans on the SSE affect volatility. The remaining controls are included to account for industry, country-specific, and Europe-wide market condition changes. First differences are used for GBYield and SovRisk because standard unit-root tests indicate they are integrated of order one. All control variables are lagged one period. As in the short-window analyses, the coefficient of interest is $\beta E$, which captures the difference in each dependent variable between the pre- and post-event period. 


\section{Findings}

Table 1 presents descriptive statistics for our sample. Daily message traffic (which includes all updates to the limit order book) averages about 46,397 while average share price is 17.09 euros.

\section{[Table 1]}

In the first three subsections we examine each event individually: the introduction of SIBE-Smart (Section 6.1), the two short-sale bans (Section 6.2), and colocation (Section 6.3). In Section 6.4 we present the overall effects from before the first change is introduced to after all of the changes are completed, to determine the net effect of technology upgrades and the bans on market quality.

\subsection{Effects of the introduction of SIBE-Smart}

SIBE-Smart was introduced on April 16, 2012 to seamlessly connect the SSE with the other European exchanges and facilitate high-speed trading. According to the SSE (Bolsa, 2012), the SIBE-Smart introduction reduced latency from about 7 milliseconds in 2011 to less than 1 millisecond. ${ }^{8}$ To evaluate the impact of this technological upgrade and the resulting faster trading platform, we compute and test for differences in the measures of various dimensions of liquidity and market activity by comparing the pre-SIBE-Smart (March 1, 2012 - April 15, 2012) and post-SIBE-Smart (April 16, 2012 - May 31, 2012) periods. Results are presented first for the short window (five days before to five days after) in Panel A and then for the long window in Panel B.

\section{[Table 2]}

\footnotetext{
${ }^{8}$ https://www.bolsasymercados.es/esp/publicacion/revista/revista.htm (last access: November 11, 2016).
} 
Panel A of Table 2 shows that although trading volume and the number of trades increase, there is an overall reduction in liquidity with spreads increasing and depth decreasing, leading to a decrease in LOB elasticity. To ascertain whether this short-run effect is temporary and traders adjust to the smart platform over time, we next examine a longer time window surrounding the introduction of SIBE-Smart. Panel B shows that these effects are not reversed in the long run. The slight increase in trading volume and the number of trades over the short run peters out, while liquidity continues to worsen, with effective spreads increasing, depth decreasing, and LOB elasticity decreasing. The alignment of the short- and long-run results indicate that the introduction of the SIBESmart platform leads to an unambiguous reduction in market liquidity, as measured by spreads, depths, and LOB elasticity, while not boosting market activity much.

We next ask if there are any other benefits to this technological upgrade in terms of reduction in return volatility and/or improvements in price efficiency, in either the short or the long event windows. Results are reported in Table 3.

\section{[Table 3]}

Panel A shows significant increases in realized volatility, return autocorrelation, and standard deviation of pricing errors in both the short and the long windows. We do not find any evidence that the introduction of the SIBE-Smart platform helps improve the informativeness of prices by reducing pricing errors. Thus, our results are different from Riordan and Storkenmaier (2012), who find that prices become more efficient after a technology upgrade on the Deutsche Boerse.

In Panel B of Table 3 we examine the effect of this technological upgrade on the realized spreads and price impacts of trades. In both the short- and long-window analyses, realized spreads and price impacts increase. Thus the increase in effective spreads 
documented in Table 2 (Panel A for short and Panel B for long window) are driven by a combination of higher profits to liquidity suppliers (realized spreads) and higher adverse selection (price impacts). Our results again differ from Riordan and Storkenmaier (2012), who find liquidity improvements due to a reduction in adverse selection after a similar technological upgrade. In contrast, and similar to our findings, Menkveld and Zoican (2017) find that for a NASDAQ-OMX speed upgrade, spreads increase, possibly due to increased speculative trading by high-frequency "bandits" who increase adverse selection costs. In our setting, it is likely that the effect of impending regulatory uncertainties (the second short-sale ban) countervails the positive effects of technology upgrades that accrue during normal times.

Much of the literature on technological upgrades in trading traces the market effect of such improvements to the presence of fast traders. Thus we next examine whether the introduction of the SIBE-Smart platform succeeded in attracting high-speed traders (the SSE's stated goal). In Table 4 we present results on the changes in our metrics for fast trading after the implementation of the SIBE-Smart trading platform.

\section{[Table 4]}

In Panel A, we find that in the short window immediately after the event, fast trading declines by all measures. Over the longer window (Panel B) only two of our six high-speed trading metrics (QIntVSh and QIntTrd) show slight increases, while the message-traffic-based and the cancellation-based metrics show no significant change. Thus the evidence points to the SIBE-Smart trading platform having only modest, if any, success in attracting high-speed trading even over the longer run.

Overall, the results are consistent with liquidity reduction in the SSE stocks during this period in spite of the introduction of the SIBE-Smart platform. Perhaps worries about 
the impending second short-sale ban weighed on the markets and led to the deterioration in market quality. Both the short- and the long-window results support the conclusion that the introduction of the SIBE-Smart trading platform generally did not attract additional fast trading.

\subsection{Short-sale ban effects under different latency regimes}

The SSE imposed short-sale bans twice during our sample period. The first ban begins on August 11, 2011 and ends on February 15, 2012, and it affects 16 stocks from the financial sector. There are no technological changes introduced during this ban. The second short-sale ban begins on July 23, 2012, and ends on January 31, 2013, affecting all the SIBE-listed stocks. Boehmer, Jones, and Zhang (2013) hypothesize that the negative impact of short-sale bans on market quality should be exacerbated in a lowlatency setting. Our setting provides an opportunity to test Boehmer et al.'s hypothesis, as the latency-reducing introduction of SIBE-Smart occurs after the first short-sale ban and before the second. We thus evaluate the impact of the second short-sale ban on market quality relative to the impact of the first short-sale ban. However, while the second ban is in effect, the SSE introduces colocation on November 12, 2012. To control for this potentially relevant event, we limit the post-event period for the second short-sale ban from July 23, 2012 to November 11, 2012.

As in previous tests, we use the pooled regression model of Eq (2), with an indicator for the second short-sale ban (SSB2), to capture the incremental difference in each variable of interest during SSB2 compared to SSB1. Our results indicate that all liquidity and market activity experience significant reductions during the second ban relative to their levels during the first ban. Return autocorrelations and pricing errors increase, indicating lower price efficiency, while realized volatility shows no change. We also find 
increased realized spreads and price impacts during the second short-sale ban relative to the first ban. Thus our findings support Boehmer et al.'s (2013) hypothesis that a shortsale ban imposed in a market with reduced latency exacerbates the negative effects of the bans on market quality. Finally, we find that four of our six high-speed trading proxies show a reduction and the other two show insignificant changes, indicating that relative to the first ban, there is an additional decline in fast trading during the second ban. The results of these tests, presented in Appendix Tables II and III, show that while both shortsale bans have negative effects on market quality, the second ban's effects were comparatively larger in magnitude. We remind readers that while the first short-sale ban affected only financial stocks, the second ban affected all stocks. Hence all results in Appendix Tables II and III should be interpreted in that context. We further note that in Section 7 we report robustness tests that include only financial stocks.

\subsection{Effects of the introduction of colocation}

The SSE introduced colocation services on November 12, 2012 to futher facilitate high-speed trading. Prior research finds that colocation leads to improved market quality (e.g., Frino, Mollica, and Webb, 2014). The unique feature of the SSE's introduction of colocation is that it happens while the SSE has a regulatory short-sale ban in effect. The second short-sale ban begins on July 23, 2012 and ends on January 31, 2013.

In this section, we test for differences in market quality before and after colocation. As with the SIBE-Smart event, we examine whether this technology upgrade has a different impact in the short run versus the long run. We begin by conducting a shortwindow (five days before and five days after) analysis and track changes in market quality immediately following the introduction of colocation. Results are presented in Panel A of Table 5. 


\section{[Table 5]}

In the short window (Panel A), there is no significant change in effective spread or depth although order book elasticity declines significantly. To examine whether these market quality effects persist in the long run, we next consider a longer event window. To clearly identify the effects of the ban and colocation, we include three time dummies in our regression: the first period from July 23, 2012 to November 11, 2012 is the precolocation period while SSB2 is in effect (Pre-Colo\&Ban); the second period from November 12, 2012 to January 31, 2013 is a time with banned short selling but availability of colocation (Colo\&Ban); and the third period from February 1, 2013 to June 30, 2013 is a time after the lifting of SSB2 when colocation is available (Colo\&PostBan). These three dummies compare the incremental effects of SSB2 and colocation compared to the benchmark period April 16, 2012 - July 22, 2012, which is a pre-ban and pre-colocation period. These dummies together can provide a complete picture of how colocation affects the SSE stocks with versus without a short-sale ban. Results are presented in Panel B of Table 5 .

The coefficients on the Pre-Colo\&Ban dummy show an increase in effective spreads and a decrease in LOB elasticity, indicating a reduction in liquidity after SSB2 is imposed. This negative impact on market quality is partly reversed after the introduction of colocation while SSB2 is still in effect. The Colo\&Ban dummy coefficients indicate that effective spreads are still above the levels prevailing before SSB2 was imposed, but the depth dimension substantially improves. The LOB elasticity, which is a summary measure encompassing both spread and depth, shows that colocation improves liquidity. The F-tests comparing the Pre-Colo\&Ban and the Colo\&Ban coefficients confirm that the market quality improvement after introducing colocation services is significant, although there is no change in trading activity. The Colo\&Post-Ban coefficients show 
that once SSB2 is lifted and with colocation in place, market quality improves with respect to the pre-ban and pre-colocation period in terms of effective spread and depth. The F-tests comparing the Colo\&Ban and Colo\&Post-Ban coefficients confirm that effective spreads are significantly lower and LOB elasticity is significantly higher after the ban is lifted and while colocation is still in effect.

\section{[Table 6]}

Table 6 shows that the effects of colocation on volatility, pricing efficiency, realized spreads, and price impact differ over the two horizons. In the short window (Panel A), volatility and price impact increase and realized spreads decline after colocation is introduced during SSB2. In the long window (Panel B), with respect to the pre-ban period, we observe no significant effect on realized volatility and the price impact of trades right after SSB2 is imposed (Pre-Colo\&Ban dummy). Realized spreads increase and price efficiency slightly deteriorates. The Colo\&Ban coefficients show that, once colocation is introduced, with the ban still in place, realized volatility and the price impact of trades both decline. Return autocorrelations increase significantly, indicating that price efficiency deteriorates. Realized spreads remain above pre-ban levels. According to the F-tests, the introduction of colocation with the ban in place reduces volatility and price impact and decreases price efficiency. Finally, the Post-Colo\&Ban coefficients indicate that, once the ban is lifted and with colocation in place, realized volatility and price impact decline with respect to the pre-ban control period, with no notable effect on either price efficiency or realized spreads. Compared to the Colo\&Ban period, the F-tests show that lifting the ban enhances the benefits of colocation in terms of lower volatility, with price efficiency and realized spreads returning to pre-ban levels. Overall, the introduction of colocation leads to improved market quality in terms of higher liquidity, lower realized volatility and price impact of trades, even while the second short-sale ban is still in effect. 
We also examine whether colocation helps attract high-speed traders to the SSE market, which was the SSE's stated goal, in Table 7.

\section{[Table 7]}

Panel A of Table 7 shows no significant change in high-speed trading in the short window. In Panel B, the long-window results show that the coefficients on the PreColo\&Ban dummy are negative and significant for all six metrics of high-speed trading, indicating that compared to the pre-ban period, the period after the ban is imposed (but before colocation is introduced) sees a reduction in fast trading. The coefficents on the Colo\&Ban dummy are also significantly negative for all of the high-speed trading metrics. In fact, the magnitudes are greater for these coefficients, indicating that highspeed trading is even lower after the introduction of colocation. Thus, the introduction of colocation while the ban was in effect sees a reduction in fast trading. The F-tests comparing the Pre-Colo\&Ban and the Colo\&Ban dummies confirm this finding, with all of the coefficients statistically smaller after colocation than before colocation at least at the 5\% level. Once SSB2 is lifted, in a regime with colocation facilities available, the Colo\&Post-Ban dummy shows that there is no increase in high-speed trading with respect to the control period. Thus, the negative effects of SSB2 on high-speed trading are not reversed even after the ban is lifted.

The results in this section show that unlike the SIBE-Smart platform upgrade, colocation has a generally positive effect on market quality. These contrasting results highlight how the regulatory regime can impact the effect of infrastructure upgrades on market quality outcomes. Finally, in the next section we examine the overall effects of these regulatory restrictions and the technological upgrades taken together. 


\subsection{Effects of all events combined}

In Table 8 we examine changes in liquidity and market activity (Panel A), volatility and price efficiency (Panel B) and high-speed trading activity (Panel C) on the SSE before and after the time window that includes all of the technology changes and short-sale bans. The pre-events period is from February 1, 2011 to June 30, 2011 and the post-events period is from February 1, 2013 to June 30, 2013.

\section{[Table 8]}

Panel A shows that liquidity declines on the SSE over this period. Trade-weighted effective spread increases and limit order book elasticity decreases. There is no offsetting increase in depth; in fact, depth shows no significant change overall. The market activity measures show similar patterns: Both volume in euros and number of trades fall.

Panel B shows that there are no significant changes in volatility, pricing errors, and realized spreads, while return autocorrelations increase significantly. Price impact is significantly higher after all the changes, suggesting that informed traders are faring somewhat better in the post-changes period.

In Panel $\mathrm{C}$, most of the proxies for high-speed trading show no significant change from the pre- to post-event period; the exceptions are the cancellation-related metrics, which show a weak increase. Overall, there is little evidence of an increase in high-speed trading activity.

Thus, the overall effect appears to be that over the longer run, the negative effects of the short-sale bans outweigh the positive effects of the two technological upgrades, although these efforts at facilitating greater automation of trading generate some shortrun positive effects (especially the introduction of colocation). 


\section{Robustness checks}

We validate the results presented in this study with a number of robustness checks. All of our results hold for the subset of Blue Chip stocks (defined as the seven stocks in our sample that consistently rank in the top ten stocks by market capitalization), which previous studies document are preferred by high-speed traders. Additionally, since the first short-sale ban affected only the financial stocks, we replicate all our results for the subsample of the eight financial stocks in our sample; results are qualitatively similar. One possible explanation for these similar results is a spillover effect from the financial stocks affected by the first ban to other stocks in the IBEX-35 index; for example, traders executing index strategies may curtail their trading in all index stocks even if only some of them are subject to a short-sale ban.

We also separately examine the four Spanish stocks in our sample which are crosslisted on the NYSE (tickers BBVA, REP, SAN, and TEF). Their trades on the NYSE make up very little of their overall volume: an average of 3\% in 2011 and 3.6\% in 2013. Running separate pre- versus post-ban tests for the first and the second short-sale bans yields similar inference, with the second ban showing bigger declines in liquidity. We also compute other share- and Euro-based metrics to proxy for high-speed trading, test additional proxies for liquidity, including Amihud illiquidity and quoted bid-ask spread, and compute realized spreads and price impacts at the 15-second, 30-second, and 60second horizons. For the long-window tests, we also run a sensitivity analysis by aggregating data at intra-daily frequency.

To test that there are no changes in the level of hidden orders (which we cannot fully detect given the LOB snapshot data) around our information events, we construct two metrics. RelHidTrades is the number of trades involving hidden volume divided by 
the total number of trades; RelHidVol is the volume of trades executed involving hidden volume divided by the total volume. We then run the long-window regressions (Eq. 2) with these two variables as the dependent variable around the introduction of the SIBESmart platform and colocation. The post-event dummies and the F-tests for the dummies surrounding colocation indicate that these hidden-execution-based variables did not experience significant event-related changes. All conclusions of the robustness checks are consistent with results presented in this study, and are available upon request.

\section{Conclusions}

Existing studies show that when exchanges provide technological upgrades, there are benefits in terms of improved liquidity and price efficiency, while at the same time the fast trading attracted by these upgrades may also adversely select other investors or otherwise harm market quality. Our investigation examines the key role of regulation in this equation. We find that whether exchanges can reap market quality gains by reducing latency depends critically on the regulatory framework within which technological upgrades are implemented. In this study we identify a unique timeline of events that allow us to shed light on how market quality is affected when technological enhancements are accompanied by, or enacted during, regulatory restrictions.

During our sample period, the SSE introduced two major technological changes to attract high-speed trading: a technologically upgraded trading platform (SIBE-Smart) in April 2012 followed by colocation facilities in November 2012. During our sample period, there were two short-sale bans imposed by the SSE. The first ban ended just before the SIBE-Smart introduction, and the second ban started before the colocation event and ended several months later. We use this juxtaposition of events to examine how trading activity, market liquidity, and price efficiency are affected. 
We document several new findings. We find no significant increase in market quality over short windows around each technology upgrade. Examining a longer window, we still find that the SIBE-Smart introduction is accompanied by reductions in liquidity and price efficiency. The colocation event, which is introduced during the second short-sale ban, leads to liquidity improvements while the ban is in effect, and further gains accrue after the second short-sale ban is lifted. However, when we examine the overall changes in market quality from the period before the technological upgrades and short-sale bans to the period after, by most metrics, liquidity worsened and price efficiency fell. Furthermore, there is no increase in high-speed trading activity when comparing the periods before and after all these events. These results are in contrast to extant studies that document the unambigious positive effects of technological upgrades that are implemented in the absence of any regulatory restrictions.

When regulatory restrictions are present, as in our setting, we find that the positive effects of speed-friendly technological improvements, documented in previous studies, may or may not accrue depending on whether these upgrades are preceded, accompanied, or succeeded by the regulatory bans. We believe that our results can inform regulators as they debate imposing trading restrictions in markets that have adopted technologies to facilitate high-speed trading. 


\section{References}

Aitken, M.J., A. Aspris, S. Foley, F.H. deB. Harris, 2015, Market fairness: the poor country cousin of market efficiency, Journal of Business Ethics, forthcoming.

Baron, Matthew, Jonathan Brogaard, and Andrei Kirilenko, 2012, The trading profits of high-frequency traders, Working paper.

Battalio, Robert H., Hamid Mehran, and Paul H. Schultz, 2012, Market declines: What is accomplished by banning short-selling? Current Issues in Economics and Finance 18(5).

Beber, Alessandro, and Marco Pagano, 2013, Short-selling bans around the world: Evidence from the 2007-2009 crisis, Journal of Finance 61(8): 343-381

Bershova, Nataliya, and Dmitry Rakhlin, 2013, High-frequency trading and long-term investors: A view from the buy-side, Journal of Investment Strategies 2(2): 25-69.

Blas, Cecilio Gil, Javier González, , and Victoria Villanueva,. 2011, Desarrollos recientes de la microestructura de los mercados secundarios de acciones. CNMV Working Paper \#50.

Boehmer, Ekkehart, Kingsley Fong, and Juan (Julie) Wu, 2015, International evidence on algorithmic trading, Working paper.

Boehmer, Ekkehart, Charles M. Jones, and Xiaoyan Zhang, 2013, Shackling short sellers: The 2008 shorting ban, Review of Financial Studies 26(6): 1363-1400.

Bolsa, 2012, Nueva plataforma SIBE, 192 (2nd quarter): 36-40.

Bris, Arturo, William Goetzmann, and Ning Zhu, 2007, Efficiency and the bear: Short sales and markets around the world, Journal of Finance 62(3): 1029-1079.

Brogaard, Jonathan, 2010, High frequency trading and price volatility, Working paper.

Brogaard, Jonathan, Björn Hagströmer, Lars L. Nordén, and Ryan Riordan, 2015, Trading fast and slow: colocation and liquidity, Review of Financial Studies 28(12): 3407-3443.

Brogaard, Jonathan, Terrence Hendershott, and Ryan Riordan, 2014, High frequency trading and price discovery, Review of Financial Studies 27: 2267-2306.

Brogaard, Jonathan, Terrence Hendershott, and Ryan Riordan, 2016, High frequency trading and the 2008 short sale ban, Journal of Financial Economics, forthcoming.

Brogaard, Jonathan, Terrence Hendershott, Stefan Hunt, and Carla Ysusi, 2014, High frequency trading and the execution costs of institutional investors, The Financial Review 49: 345-369.

Cáceres, Esther, David Moreno, and Rosa Rodriguez, 2014, A study on short-selling constraints: total ban versus partial ban, Applied Economics Letters, 22(2): 99-103.

Chesini, Giusy, 2012, The pricing policies of major trading venues, Working paper.

Conrad, Jennifer, Sunil Wahal, and Jin Xiang, 2015, High-frequency quoting, trading, and the efficiency of prices, Journal of Financial Economics, 116: 271-291. 
Desai, Hemang, Srinivasan Krishnamurthy, and Kumar Venkataraman, 2006, Do short sellers target firms with poor earnings quality? Evidence from earnings restatements, Review of Accounting Studies 11(1): 71-90.

Egginton, Jared F., Bonnie F. Van Ness, and Robert A. Van Ness, 2014, Quote stuffing, Working paper.

ESMA, 2014, High frequency trading activity in EU equity markets. Economic Report $\# 1$.

Hasbrouck, Joel, 1993, Assessing the quality of a security market: A new approach to transaction-cost measurement, Review of Financial Studies 6(1): 191-212.

Hasbrouck, Joel, and Gideon Saar, 2013, Low-latency trading, Journal of Financial Markets 16: 646-679.

Hendershott, Terrence, Charles M. Jones, and Albert J. Menkveld, 2011, Does algorithmic trading improve liquidity? Journal of Finance 66: 1-33.

Hirschey, Nicholas, 2013, Do HFTs anticipate buying and selling pressures? Working Paper.

Huang and Stoll, 1996, Dealer vs auction markets: A paired comparison of execution costs on NASDAQ and the NYSE, Journal of Financial Economics 41: 313-357.

Jiang, Danling, David R. Peterson, and James S. Doran, 2014, Short-sale constraints and the idiosyncratic volatility puzzle: An event study approach, Journal of Empirical Finance 28: 36-59.

Jovanovic, Boyan, and Albert J. Menkveld, 2013, Middlemen in limit order markets, Working paper.

Karpoff, Jonathan M., and Xiaoxia Lou, 2010, Short sellers and financial misconduct, Journal of Finance 65(5): 1879-1913.

Kirilenko, Andrei, Albert S. Kyle, Mehrdad Samadi, and Tugkan Tuzun, 2014, The flash crash: The impact of high-frequency trading on an electronic market, Working paper.

Korajczyk, Robert A., and Dermot Murphy, 2015, High frequency market making to large institutional trades, Working paper.

Malinova, Katya, Andreas Park, and Ryan Riordan, 2016, Do retail traders suffer from high frequency traders? Working paper.

Menkveld, Albert J., 2013, High frequency trading and the new market makers, Journal of Financial Markets, 16: 712-740.

Menkveld, Albert J., and Marius A. Zoican, 2017, Need for speed: Exchange latency and liquidity, Review of Financial Studies, forthcoming.

Näes, Randi, and Johannes A. Skjeltorp, 2006, Order book characteristics and the volume-volatility relation: Empirical evidence from a limit order market, Journal of Financial Market 9(4): 408-432. 
Pardo, Ángel, and Roberto Pascual, 2012, On the hidden side of liquidity, European Journal of Finance 18(10): 949-967.

Riordan, Ryan, and Andreas Storkenmaier, 2012, Latency, liquidity, and price discovery, Journal of Financial Markets, 15: 416-437.

Thompson, Samuel B., 2011, Simple formulas for standard errors that cluster by both firms and time, Journal of Financial Economics, 99: 1-10.

van Kervel, Vincent, and Albert J. Menkveld, 2015, High-frequency trading around large institutional orders, Working paper. 


\section{TABLE 1 \\ Sample Statistics}

We provide average daily statistics for our full sample of 36 stocks for the period February 2011 to June 2013. We provide statistics on market capitalization; transaction price; volume in shares and euros; number of trades; relative bid-ask spreads; displayed depth at the five best levels of the LOB, both in shares and euros; the absolute open-to-close returns; the ratio between the highest and the lowest trade price, and message traffic. Standard deviations are in parentheses.

Metric

Market Cap. (/10000)

Cross-sectional average

1151334.09

(1721046.88)

Price

Volume (/10000)

(972.30)

Euro Volume (/10000)

4421.48

(7476.87)

Trades

2786.76

(2962.78)

Relative bid-ask spread

0.0016

(0.0006)

Depth

58181.41

(91080.94)

Depth (€)

385433.38

(353945.77)

Abs. open-to-close returns

0.0142

(0.0032)

Price high/low

0.0297

(0.0061)

Message Traffic

46396.96

(43541.41) 


\section{TABLE 2 \\ SIBE-Smart: Liquidity and activity}

We evaluate the impact of the introduction of the SIBE-Smart on liquidity and trading activity. In Panel A (short window), we compare a 5-day "pre-Smart" period (April 5, 2012 - April 15, 2012) and a 5-day "postSmart" period (April 16, 2012 - April 20, 2012). High-frequency data is aggregated into 30-minute intervals. In Panel B (long window), we compare the "pre-Smart" (March 1, 2012 - April 15, 2012) and "post-Smart" periods (April 16, 2012 - May 31, 2012). High-frequency data is aggregated to obtain daily statistics. We present the estimated coefficients from pooled regressions with double-clustered standard errors. Liquidity proxies are: effective spread weighted by trade size (x100) (ESpr); time-weighted quoted depth (Depth); and LOB elasticity (LOBElast). ESpr is an inverse measure while Depth and LOBElast are direct measures of liquidity. Market activity proxies are: the daily volume in shares $(\mathrm{Vol})\left(/ 10^{4}\right)$; the daily volume in euros (Vol€) $\left(/ 10^{6}\right)$, and the daily number of trades (Trades). In both panels, the explanatory variable of interest is the dummy for the post-Smart period ("Post-Smart"). In Panel A, intraday dummies are unreported. In Panel B, control variables include the IBEX-35 volatility (Volat-1), the IBEX-35 daily return $\left(\right.$ XRet $\left._{-1}\right)$, the first difference of the long-term Government debt yield of Spain $\left(\triangle G B Y\right.$ ield $\left._{-1}\right)$, the first difference of the sovereign risk of Spain ( $\triangle$ SovRisk $_{-1}$ ), measured as the spread between the long-term Government debt yield of Spain and Germany, and industrial sector dummies (not reported). All controls are lagged one period.

Panel A: Liquidity and Market activity - Short window

\begin{tabular}{lccccrc}
\hline Variable & ESpr & Depth & LOBElast & Vol & Vol€ & Trades \\
\hline Cons. & $0.2155 * * *$ & $1334.59 * * *$ & $112.20 * * *$ & $43.81 * * *$ & $298.74 * * *$ & $205.05 * * *$ \\
Post-Smart & $0.0132 * * *$ & $-76.14 * * *$ & $-12.42 * * *$ & $6.37 * * *$ & $34.68 * * *$ & $18.77 * * *$ \\
Obs. & 6092 & 6061 & 6096 & 6051 & 6067 & 6055 \\
Adj.-R2 & 0.1013 & 0.0194 & 0.0460 & 0.0158 & 0.0200 & 0.0306 \\
F & 69.86 & 50.92 & 118.20 & 25.72 & 29.01 & 55.03
\end{tabular}

Panel B: Liquidity and Market activity - Long window

\begin{tabular}{lcccccc}
\hline Variable & ESpr & Depth & LOBElast & Vol & Vol€ & Trades \\
\hline Cons. & $0.1022 * * *$ & $1994.12 * * *$ & $218.56 * * *$ & $446.55 * * *$ & $34.55 * * *$ & $25.65 * * *$ \\
Post-Smart & $0.0424 * * *$ & $-447.10 * * *$ & $-36.81 * * *$ & 68.52 & -1.31 & 2.03 \\
Volat $_{-1}$ & $0.0038 * * *$ & -70.67 & -10.03 & 32.78 & 1.39 & 1.28 \\
XRet $_{-1}$ & -0.0005 & 3.26 & 0.7362 & -28.7640 & -1.6388 & -1.4805 \\
$\Delta$ GBYield $_{-1}$ & 0.0034 & 817.84 & 74.06 & -41.57 & -7.10 & 5.60 \\
$\Delta$ SovRisk $_{-1}$ & 0.0001 & -6.4704 & -0.5901 & -1.94 & -0.09 & -0.14 \\
Obs. & 2139 & 2139 & 2139 & 2139 & 2139 & 2139 \\
Adj.-R2 & 0.0686 & 0.0329 & 0.0573 & 0.0011 & -0.0009 & 0.0033 \\
F & 35.68 & 14.77 & 26.05 & 1.31 & 0.51 & 1.98 \\
\hline$* * *, * *{ }^{*}$ indicates statistically significant at the $1 \%, 5 \%$ and $10 \%$ level, respectively. & &
\end{tabular}


TABLE 3

SIBE-Smart: Volatility, price efficiency, realized spreads, and price impact

We evaluate the impact of the introduction of the SIBE-Smart on volatility and price efficiency (Panel A), and realized spreads and price impacts (Panel B). In the long-window analysis, we compare the "pre-Smart" (March 1, 2012 - April 15, 2012) and "post-Smart" (April 16, 2012 - May 31, 2012) periods. In the shortwindow analysis, we compare a 5-day "pre-Smart" period (April 5, 2012 - April 15, 2012) and a 5-day "post-Smart" period (April 16, 2012 - April 20, 2012). Realized volatility (RVolat) is the daily standard deviation of 1-minute trade price returns (x100). Efficiency proxies are the autocorrelation of 1-minute trade price returns (Corr) and the pricing error standard deviation (PrErr), estimated using Hasbrouck (1993). Price impact (PrImp) measures the informativeness of trades (adverse selection cost), and the realized spread $(R S p r)$ measures how much of the effective spread is earned by the liquidity provider. Price impact and realized spread are measured over a 5-second horizon after the trade. The explanatory variable of interest is the dummy for the post-Smart period ("Post-Smart"). In the long-window analysis, we use as controls the IBEX-35 volatility (Volat-1), the IBEX-35 daily return (XRet-1), the first difference of the longterm Government debt yield of Spain $(\triangle$ GBYield -1$)$, the first difference of the sovereign risk of Spain ( $\triangle$ SovRisk-1), measured as the spread between the long-term Government debt yield of Spain and Germany, and industrial sector dummies (not reported). All controls are lagged one period.

Panel A: Realized volatility and price efficiency

\begin{tabular}{|c|c|c|c|c|c|c|}
\hline \multirow[b]{2}{*}{ Variable } & \multicolumn{3}{|c|}{ Short Window results } & \multicolumn{3}{|c|}{ Long Window results } \\
\hline & RVolat & Corr & PrErr & RVolat & Corr & PrErr \\
\hline Cons. & $0.1974 * * *$ & $16.379 * * *$ & $0.0367 * * *$ & $0.0879 * * *$ & $0.0676 * * *$ & $0.0226 * * *$ \\
\hline Post-Smart & $0.0151 * * *$ & $0.745 * *$ & $0.0040 * * *$ & $0.0340 * * *$ & $0.0136 * * *$ & $0.0102 * * *$ \\
\hline Volat_1 $_{1}$ & N/A & N/A & N/A & $0.0073 * * *$ & -0.0013 & $0.0008 * * *$ \\
\hline XRet $_{-1}$ & N/A & N/A & N/A & $-0.0031 * * *$ & -0.0013 & $-0.0004 *$ \\
\hline$\Delta$ GBYield $_{-1}$ & N/A & N/A & N/A & -0.0256 & 0.0134 & 0.0063 \\
\hline$\Delta$ SovRisk $_{-1}$ & N/A & N/A & N/A & 0.0001 & -0.0003 & $0.0001 * * *$ \\
\hline Obs. & 6103 & 6116 & 3225 & 2139 & 2139 & 2139 \\
\hline Adj.- $\mathrm{R}^{2}$ & 0.2057 & 0.0055 & 0.0753 & 0.1751 & 0.011 & 0.0712 \\
\hline $\mathrm{F}$ & 138.85 & 1.99 & 44.06 & 95.47 & 5.76 & 35.48 \\
\hline
\end{tabular}

Panel B: Realized spread and price impact

\begin{tabular}{|c|c|c|c|c|c|}
\hline \multirow[b]{2}{*}{ Variable } & \multicolumn{3}{|c|}{ Short Window results } & \multicolumn{2}{|c|}{ Long Window results } \\
\hline & RSpr5 & & PrImp5 & RSpr5 & PrImp5 \\
\hline Cons. & 0.0581 & $* * *$ & $0.1248 * * *$ & $0.0390 * * *$ & $0.0543 * * *$ \\
\hline Post-Smart & 0.0044 & $* * *$ & $0.0087 \quad * * *$ & $0.0085 *$ & $0.0230 * * *$ \\
\hline Volat $_{-1}$ & $\mathrm{~N} / \mathrm{A}$ & & $\mathrm{N} / \mathrm{A}$ & $-0.0028 * *$ & $0.0057 * * *$ \\
\hline XRet $_{-1}$ & $\mathrm{~N} / \mathrm{A}$ & & N/A & 0.0001 & -0.0007 \\
\hline$\Delta$ GBYield $_{-1}$ & $\mathrm{~N} / \mathrm{A}$ & & N/A & 0.0289 & -0.0297 \\
\hline$\Delta$ SovRisk $_{-1}$ & $\mathrm{~N} / \mathrm{A}$ & & $\mathrm{N} / \mathrm{A}$ & -0.0001 & 0.0002 \\
\hline Obs. & 6102 & & 6095 & 2139 & 2139 \\
\hline Adj.- $R^{2}$ & 0.0548 & & 0.0779 & 0.0979 & 0.3466 \\
\hline $\mathrm{F}$ & 26.43 & & 45.23 & 39.68 & 111.72 \\
\hline
\end{tabular}

$* * *, * *, *$ indicates statistically significant at the $1 \%, 5 \%$ and $10 \%$ level, respectively. 


\section{TABLE 4 \\ SIBE-Smart: High-speed trading}

We evaluate the impact of the introduction of the SIBE-Smart on high-speed trading. In Panel A (short window), we compare a 5-day "pre-Smart" period (April 5, 2012 - April 15, 2012) and a 5-day "postSmart" period (April 16, 2012 - April 20, 2012). High-frequency data is aggregated into 30-minute intervals. In Panel B (long window), we compare the "pre-Smart" (March 1, 2012 - April 15, 2012) and "post-Smart" periods (April 16, 2012 - May 31, 2012). High-frequency data is aggregated to obtain daily statistics. This table presents the estimated coefficients from pooled regressions with double-clustered standard errors. HFT proxies are: message traffic per volume in shares (MTVSh), message traffic per trade $(M T T r d)$, cancellations per volume in shares (CANVSh), cancellations per trade (CANTrd), quote intensity per volume in shares (QIntVSh), and quote intensity per trade (QIntTrd). Message traffic is the total number LOB updates, which is equivalent to sum all order submissions, revisions, and cancellations. Quote intensity is measured by the number of quote or depth changes at the market quotes. The explanatory variable of interest is the dummy for the post-Smart period ("Post-Smart"). Intraday dummies are not reported. In Panel B, we use as controls the IBEX-35 volatility (Volat-1), the IBEX-35 daily return (XRet. 1), the first difference of the long-term Government debt yield of Spain ( $\triangle$ GBYield -1$)$, the first difference of the sovereign risk of Spain ( $\triangle$ SovRisk-1), measured as the spread between the long-term Government debt yield of Spain and Germany, and industrial sector dummies (not reported). All controls are lagged one period.

Panel A: High-speed trading metrics - Short window

\begin{tabular}{|c|c|c|c|c|c|c|}
\hline Variable & MTVSh & MTTrd & CANVSh & CANTrd & QIntVSh & QIntTrd \\
\hline Cons. & $0.0787 * * *$ & $37.6219^{* * *}$ & $0.0324 * * *$ & $15.16 * * *$ & $0.0361 * * *$ & $16.57 * * *$ \\
\hline Post-Smart & $-0.0172 * * *$ & $-5.4778 * * *$ & $-0.0063 * * *$ & $-1.52 * *$ & $-0.0076 * *$ & $-1.90 * *$ \\
\hline Obs. & 6070 & 6068 & 5978 & 5963 & 5990 & 5980 \\
\hline Adj.-R2 & 0.0052 & 0.0067 & 0.0039 & 0.0027 & 0.0037 & 0.0041 \\
\hline $\mathrm{F}$ & 32.72 & 42.15 & 24.25 & 16.88 & 22.79 & 25.45 \\
\hline \multicolumn{7}{|c|}{ Panel B: High-speed trading metrics - Long window } \\
\hline Variable & MTVSh & MTVTrd & CANVSh & CANTrd & QIntVSh & QIntTrd \\
\hline Cons. & $0.0491 * * *$ & $25.564 * * *$ & $0.0207 * * *$ & $10.757 * * *$ & $0.0223 * * *$ & $11.4821 * * *$ \\
\hline Post-Smart & 0.0111 & 2.235 & 0.0042 & 0.976 & $0.0104 *$ & $3.2497 * *$ \\
\hline Volat $_{-1}$ & -0.0010 & 0.416 & $-0.0005 *$ & 0.084 & -0.0003 & 0.3885 \\
\hline XRet $_{-1}$ & 0.0015 & $0.436 * *$ & 0.0007 & $0.200 * *$ & 0.0009 & $0.3008 * *$ \\
\hline$\Delta$ GBYield $_{-1}$ & 0.0288 & 4.669 & 0.0113 & 1.838 & 0.0067 & -1.2651 \\
\hline$\Delta$ SovRisk $_{-1}$ & 0.0000 & 0.047 & 0.0000 & 0.023 & 0.0001 & 0.0432 \\
\hline Obs. & 2139 & 2139 & 2131 & 2131 & 2131 & 2131 \\
\hline Adj.-R2 & 0.0031 & 0.004 & 0.0024 & 0.0029 & 0.0116 & 0.0296 \\
\hline $\mathrm{F}$ & 2.20 & 2.743 & 1.8988 & 2.1747 & 6.2343 & 15.0958 \\
\hline
\end{tabular}

$* * *, * *, *$ indicates statistically significant at the $1 \%, 5 \%$ and $10 \%$ level, respectively. 
TABLE 5

\section{Colocation: Liquidity and market activity}

We study the impact of introducing colocation services on liquidity and trading activity. In Panel A (short window), we compare a 5-day "pre-colocation" period (November 5-11, 2012) and a 5-day "postcolocation" period (November 12-16, 2012). High-frequency data is aggregated into 30-minute intervals. In Panel B (long window), we compare three periods: the "Pre-Colo\&Ban" period spans from July 23, 2013 to November 11, 2012, a time with banned short selling and no colocation; the "Colo\&Ban" period spans from November 12, 2012 to January 31, 2013, a time with banned short selling and colocation, and the "Colo\&Post-Ban" period corresponds to February 1, 2013 - June 31, 2013, a time with no ban but with colocation. The control period is April 16, 2012 - July 22, 2012, the time between the introduction of the SIBE-Smart platform and the ban imposition. In Panel B, high-frequency data is aggregated into daily statistics. We present the estimated coefficients from pooled regressions with double-clustered standard errors. Liquidity proxies are: effective spread weighted by trade size (x100) (ESpr); time-weighted quoted depth (Depth); and LOB elasticity (LOBElast). ESpr is an inverse measure while Depth and LOBElast are direct measures of liquidity. Market activity proxies are: the daily volume in shares $(\mathrm{Vol})\left(/ 10^{4}\right)$; the daily volume in euros (Vol€) $\left(/ 10^{6}\right)$, and the daily number of trades (Trades). In Panel A, the explanatory variable of interest is the dummy for the post-colocation period ("Post-Colo"). Intraday dummies are unreported. In Panel B, the variables of interest are the dummies for the Pre-Colo\&Ban, Colo\&Ban, and Colo\&Post-Ban periods. We report F-tests comparing the estimated coefficients. Control variables include the IBEX-35 volatility (Volat-1), the IBEX-35 daily return (XRet-1), the first difference of the long-term Government debt yield of Spain ( $\triangle$ GBYield -1$)$, the first difference of the sovereign risk of Spain ( $\triangle$ SovRisk $\left._{-1}\right)$, measured as the spread between the long-term Government debt yield of Spain and Germany, and industrial sector dummies (not reported). All controls are lagged one period.

\begin{tabular}{|c|c|c|c|c|c|c|}
\hline Variable & ESpr & Depth & LOBElast & $\mathrm{Vol}$ & Vol€ & Trades \\
\hline Cons. & $0.2604 * * *$ & $809.13 * * *$ & $90.95 * * *$ & $19.44 * * *$ & $116.39 * * *$ & $84.87 * * *$ \\
\hline Post-Colo & 0.0010 & -21.99 & $-6.7141 * * *$ & $3.28 * * *$ & 0.0164 & 0.8856 \\
\hline Obs. & 6037 & 6094 & 6082 & 6114 & 6115 & 6110 \\
\hline Adj.-R2 & 0.0477 & 0.0290 & 0.0477 & 0.0226 & 0.0312 & 0.0424 \\
\hline $\mathrm{F}$ & 29.75 & 29.26 & 60.22 & 19.48 & 29.94 & 44.74 \\
\hline \multicolumn{7}{|l|}{ Panel B: Long window } \\
\hline Variable & ESpr & Depth & LOBElast & $\mathrm{Vol}$ & Vol€ & Trades \\
\hline Cons. & $0.1858 * * *$ & $731.087 * * *$ & $113.895 * * *$ & 72.883 & $9.452 * * *$ & $13.373 * * *$ \\
\hline Pre-Colo\&Ban [1] & $0.0529 * * *$ & 51.049 & $-20.680 * * *$ & $-199.413 * * *$ & $-11.026 * * *$ & $-11.570 * * *$ \\
\hline Colo\&Ban & $0.0269 * * *$ & $719.668 * *$ & $18.817 * * *$ & -40.290 & $-10.508 * *$ & $-11.135 * * *$ \\
\hline Colo\&Post-Ban & $-0.0170 *$ & $542.303 * *$ & $41.465 * * *$ & 17.259 & $-4.227 *$ & $-47.365 * * *$ \\
\hline Volat $_{-1}$ & $0.0095 * * *$ & -36.107 & $-5.694 * * *$ & $35.405 * * *$ & $1.663 * * *$ & $1.655 * * *$ \\
\hline XRet $_{-1}$ & 0.0003 & $44.885 * *$ & $1.087 * * *$ & -1.832 & -0.036 & -0.253 \\
\hline$\Delta$ GBYield $_{-1}$ & 0.0072 & -180.819 & $11.633 * *$ & -57.451 & $-5.199 * * *$ & -1.950 \\
\hline$\Delta$ SovRisk $_{-1}$ & 0.0021 & -0.3348 & $-0.0579 * *$ & 0.1549 & 0.0131 & -0.019 \\
\hline Obs. & 10514 & 10514 & 10514 & 10514 & 10514 & 10514 \\
\hline Adj.-R2 & 0.2451 & 0.0595 & 0.2248 & 0.1942 & 0.1452 & 0.1690 \\
\hline $\mathrm{F}$ & 287.499 & 83.83 & 351.61 & 173.028 & 197.656 & 198.592 \\
\hline \multicolumn{7}{|l|}{ Coefficient tests } \\
\hline$[2]-[1]$ & -0.0260 & 668.6195 & 39.4964 & 159.1226 & 0.5179 & 0.4353 \\
\hline $\mathrm{F}$ & 6.7800 & 4.3000 & 33.2000 & 0.7800 & 0.1200 & 0.1800 \\
\hline $\mathrm{p}$-value & 0.0092 & 0.0382 & 0.0000 & 0.3782 & 0.7289 & 0.6755 \\
\hline$[3]-[2]$ & -0.0439 & -177.3650 & 22.6481 & 57.5493 & 6.2804 & -36.2302 \\
\hline $\mathrm{F}$ & 45.2400 & 0.5200 & 34.1500 & 1.3700 & 7.8600 & 17.4900 \\
\hline $\mathrm{p}$-value & 0.0000 & 0.4699 & 0.0000 & 0.2413 & 0.0051 & 0.0000 \\
\hline
\end{tabular}

$* * *, * * *$ indicates statistically significant at the $1 \%, 5 \%$ and $10 \%$ level, respectively. 
TABLE 6

\section{Colocation: Volatility, price efficiency, realized spreads, and price impacts}

We study the impact of introducing colocation services on volatility, price efficiency, realized spread, and price impact. In Panel A (short window), we compare a 5-day "pre-colocation" period (November 5-11, 2012) and a 5-day "post-colocation" period (November 12-16, 2012). High-frequency data is aggregated into 30-minute intervals. In Panel B (long window), we compare three periods: the "Pre-Colo\&Ban" period spans from July 23, 2013 to November 11, 2012, a time with banned short selling and no colocation; the "Colo\&Ban" period spans from November 12, 2012 to January 31, 2013, a time with banned short selling and colocation, and the "Colo\&Post-Ban" period corresponds to February 1, 2013 - June 31, 2013, a time with no ban but with colocation. The control period is April 16, 2012 - July 22, 2012, the time between the introduction of the SIBE-Smart and the ban imposition. In Panel B, high-frequency data is aggregated into daily statistics. We present the estimated coefficients from pooled regressions with double-clustered standard errors. Realized volatility (RVolat) is the daily standard deviation of 1-minute trade price returns (x100). Efficiency proxies are the autocorrelation of 1-minute trade price returns (Corr) and the pricing error standard deviation (PrErr), estimated using Hasbrouck (1993). Price impact (PrImp) measures adverse selection cost, and the realized spread (RSpr) measures how much of the effective spread is earned by the liquidity provider. In Panel A, the explanatory variable of interest is the post-colocation period dummy ("Post-Colo"). Intraday dummies are unreported. In Panel B, the explanatory variables of interest are the Pre-Colo\&Ban, Colo\&Ban, and Colo\&Post-Ban dummies. We report F-tests comparing the estimated coefficients. Control variables include the IBEX-35 volatility (Volat -1$)$, the IBEX-35 daily return (XRet ${ }_{-1}$ ), the first difference of the long-term Government debt yield of Spain ( $\triangle$ GBYield ${ }_{-1}$ ), the first difference of the sovereign risk of Spain ( $\Delta$ SovRisk-1), measured as the spread between the long-term Government debt yield of Spain and Germany, and industrial sector dummies (not reported). All controls are lagged one period.

\begin{tabular}{|c|c|c|c|c|c|}
\hline Variable & RVolat & Corr & PrErr & RSpr5 & PrImp5 \\
\hline Cons. & $0.1560 * * *$ & $15.04 * * *$ & $0.0430 * * *$ & $0.0827 * * *$ & $0.1222 * * *$ \\
\hline Post-Colo & $0.0072 * * *$ & 0.216 & 0.0012 & $-0.0072 * * *$ & $0.0060 * * *$ \\
\hline Obs. & 6093 & 5998 & 2820 & 5993 & 6058 \\
\hline Adj.-R2 & 0.1143 & 0.0051 & 0.0286 & 0.0127 & 0.0529 \\
\hline $\mathrm{F}$ & 58.90 & 1.80 & 14.57 & 6.10 & 26.70 \\
\hline \multicolumn{6}{|l|}{ Panel B: Long window } \\
\hline Variable & RVolat & Corr & PrErr & RSpr5 & PrImp5 \\
\hline Cons. & $0.1218 * * *$ & $0.0688 * * *$ & $0.3482 * *$ & $0.044 * * *$ & $0.1024 * * *$ \\
\hline Pre-Colo\&Ban & -0.0021 & 0.0005 & $0.1937 *$ & $0.0377 * * *$ & 0.0008 \\
\hline Colo\&Ban & $-0.0203 * * *$ & $0.0119 * * *$ & -0.0007 & $0.0354 * * *$ & $-0.0205 * * *$ \\
\hline Colo\&Post-Ban [3] & $-0.0288 * * *$ & -0.0012 & -0.0153 & 0.0050 & $-0.0214 * * *$ \\
\hline Volat $_{-1}$ & $0.0124 * * *$ & $0.0020 * * *$ & $-0.0442 *$ & 0.0010 & $0.0066 * * *$ \\
\hline XRet $_{-1}$ & -0.0008 & 0.0001 & 0.0157 & $0.0011 * *$ & $-0.0009 *$ \\
\hline$\Delta$ GBYield $_{-1}$ & -0.0144 & -0.0075 & 0.3243 & -0.0023 & 0.0044 \\
\hline$\Delta$ SovRisk $_{-1}$ & 0.0002 & 0.0001 & -0.0009 & 0.0020 & 0.0014 \\
\hline Obs. & 10514 & 10514 & 10514 & 10514 & 10514 \\
\hline Adj.-R2 & 0.2988 & 0.0094 & 0.0012 & 0.2548 & 0.275 \\
\hline F & 343.42 & 8.78 & 5.94 & 350.38 & 300.06 \\
\hline \multicolumn{6}{|l|}{ Coefficient tests } \\
\hline [2]-[1] & -0.0182 & 0.0114 & -0.1944 & -0.0023 & -0.0213 \\
\hline $\mathrm{F}$ & 15.2600 & 17.0600 & 2.0200 & 0.2400 & 38.8600 \\
\hline $\mathrm{p}$-value & 0.0001 & 0.0000 & 0.1554 & 0.6221 & 0.0000 \\
\hline [3]-[2] & -0.0085 & -0.0131 & -0.0146 & -0.0304 & -0.0009 \\
\hline $\mathrm{F}$ & 7.8200 & 16.7900 & 0.0400 & 88.4700 & 0.1300 \\
\hline $\mathrm{p}$-value & 0.0052 & 0.0000 & 0.8488 & 0.0000 & 0.7208 \\
\hline
\end{tabular}

$* * *, * *, *$ indicates statistically significant at the $1 \%, 5 \%$ and $10 \%$ level, respectively. 


\section{TABLE 7 \\ Colocation: High-speed trading}

We study the impact of introducing colocation services on high-speed trading. In Panel A (short window), we compare a 5-day "pre-colocation" period (November 5-11, 2012) and a 5-day "post-colocation" period (November 12-16, 2012). High-frequency data is aggregated into 30-minute intervals. In Panel B (long window), we compare three periods: the "Pre-Colo\&Ban" period spans from July 23, 2013 to November 11,2012 , a time with banned short selling and no colocation; the "Colo\&Ban" period spans from November 12, 2012 to January 31, 2013, a time with banned short selling and colocation, and the "Colo\&Post-Ban" period corresponds to February 1, 2013 - June 31, 2013, a time with no ban but with colocation. The control period is April 16, 2012 - July 22, 2012, the time between the introduction of the SIBE-Smart and the ban imposition. High-frequency data is aggregated into daily statistics. We present the estimated coefficients from pooled regressions with double-clustered standard errors. HFT proxies are: message traffic per volume in shares (MTVSh), message traffic per trade (MTTrd), cancellations per volume in shares (CANVSh), cancellations per trade (CANTrd), quote intensity per volume in shares (QIntVSh), and quote intensity per trade (QIntTrd). Message traffic is the total number LOB updates, the sum of all order submissions, revisions, and cancellations. Quote intensity is measured by the number of quote or depth changes at the market quotes. In Panel A, the explanatory variable of interest is the post-colocation dummy ("Post-Colo"). Intraday dummies are unreported. In Panel B, the explanatory variables of interest are the Pre-Colo\&Ban, Colo\&Ban, and Colo\&Post-Ban dummies. We report F-tests comparing the estimated coefficients. As controls, we use the IBEX-35 volatility (Volat -1$)$, the IBEX-35 daily return (XRet-1), the first difference of the long-term Government debt yield of Spain $\left(\triangle G B Y i e l d_{-1}\right)$, the first difference of the sovereign risk of Spain ( $\triangle$ SovRisk $_{-1}$ ), measured as the spread between the long-term Government debt yield of Spain and Germany, and industrial sector dummies (not reported). All controls are lagged one period.

\begin{tabular}{|c|c|c|c|c|c|c|}
\hline \multicolumn{7}{|c|}{ Panel A: Short window } \\
\hline Variable & MTVSh & MTTrd & CANVSh & CANTrd & QIntVSh & QIntTrd \\
\hline Cons. & $0.0575 * * *$ & $26.3340 * * *$ & $0.0212 * * *$ & $9.78 * * *$ & $0.0283 * * *$ & $12.42 * * *$ \\
\hline Post-Event & 0.0018 & 1.7006 & 0.0005 & 0.49 & 0.0012 & $1.16 *$ \\
\hline Obs. & 6022 & 6054 & 6028 & 6051 & 6016 & 6039 \\
\hline Adj.-R2 & -0.0001 & 0.0004 & -0.0001 & 0.0002 & -0.0001 & 0.0011 \\
\hline $\mathrm{F}$ & 0.43 & 3.45 & 0.23 & 2.05 & 0.66 & 7.79 \\
\hline \multicolumn{7}{|l|}{ Panel B: Long window } \\
\hline Variable & MTVSh & MTTrd & CANVSh & CANTrd & QIntVSh & QIntTrd \\
\hline Cons. & $0.0923 * * *$ & $37.2125 * * *$ & $0.0372 * * *$ & $14.9688 * * *$ & $19.6408 * * *$ & $0.0515 * * *$ \\
\hline Pre-Colo\&Ban & $-0.0182 * *$ & $-7.2202 * * *$ & $-0.0092 * *$ & $-3.7980 * * *$ & $-3.7408 * * *$ & $-0.0099 *$ \\
\hline Colo\&Ban & $-0.0322 * * *$ & $-11.9315 * * *$ & $-0.0146^{* * *}$ & $-5.6536 * * *$ & $-7.9533 * * *$ & $-0.0208 * * *$ \\
\hline Colo\&Post-Ban [3] & -0.0111 & -4.0449 & -0.0049 & -1.7641 & $-5.9865 * * *$ & $-0.0129 * *$ \\
\hline Volat $_{1}$ & 0.0006 & 0.1646 & 0.0003 & 0.0855 & 0.2072 & 0.0005 \\
\hline XRet $_{-1}$ & $-0.0008 *$ & $-0.4090 * *$ & $-0.0004 * *$ & $-0.1745 * *$ & $-0.2119 *$ & $-0.0004 *$ \\
\hline$\Delta$ GBY ield $_{-1}$ & 0.0063 & 3.9057 & 0.0029 & 1.7236 & 1.1283 & 0.0011 \\
\hline$\Delta$ SovRisk $_{-1}$ & 0.0001 & 0.0001 & 0.0001 & -0.0020 & 0.0041 & 0.0001 \\
\hline Obs. & 10514 & 10514 & 10514 & 10514 & 10514 & 10514 \\
\hline Adj.-R2 & 0.1550 & 0.0787 & 0.1495 & 0.0820 & 0.1159 & 0.1393 \\
\hline $\mathrm{F}$ & 195.03 & 99.94 & 173.27 & 99.30 & 107.81 & 175.45 \\
\hline \multicolumn{7}{|l|}{ Coefficient tests } \\
\hline$[2]-[1]$ & -0.0140 & -4.7113 & -0.0054 & -1.8556 & -4.2125 & -0.0109 \\
\hline $\mathrm{F}$ & 9.3600 & 6.2600 & 9.4000 & 5.9200 & 12.1300 & 13.9800 \\
\hline $\mathrm{p}$-value & 0.0022 & 0.0123 & 0.0022 & 0.0150 & 0.0005 & 0.0002 \\
\hline$[3]-[2]$ & 0.0211 & 7.8866 & 0.0097 & 3.8895 & 1.9668 & 0.0079 \\
\hline $\mathrm{F}$ & 17.5500 & 6.2200 & 17.6500 & 6.8100 & 7.1700 & 15.8400 \\
\hline $\mathrm{p}$-value & 0.0000 & 0.0127 & 0.0000 & 0.0091 & 0.0074 & 0.0001 \\
\hline
\end{tabular}

$* * *, * * *$ indicates statistically significant at the $1 \%, 5 \%$ and $10 \%$ level, respectively. 
TABLE 8

\section{All events combined}

We evaluate the net impact of the technological upgrades and short-sale bans on the SSE from 2011 to 2012 on liquidity and trading activity (Panel A), volatility, price efficiency, realized spreads, and price impact (Panel B), and high-speed trading (Panel C). We compare the "pre-events" (February 1, 2011 - June 31, 2011) and "post-events" periods (February 1, 2013 - June 31, 2013). This table presents the estimated coefficients from pooled regressions with double-clustered standard errors. High-frequency data is aggregated to obtain daily statistics. Liquidity proxies are: effective spread weighted by trade size (x100) (ESpr); time-weighted quoted depth (Depth); and LOB elasticity (LOBElast). ESpr is an inverse measure while Depth and LOBElast are direct measures of liquidity. Market activity proxies are: the daily volume in shares $(\mathrm{Vol})\left(/ 10^{4}\right)$; the daily volume in euros $(\mathrm{Vol} €)\left(/ 10^{6}\right)$, and the daily number of trades (Trades). Realized volatility (RVolat) is the daily standard deviation of 1-minute trade price returns (x100). Efficiency proxies are the autocorrelation of 1-minute trade price returns (Corr) and the pricing error standard deviation (PrErr), estimated using Hasbrouck (1993). Price impact (PrImp) measures the informativeness of trades (adverse selection cost), and the realized spread (RSpr) measures how much of the effective spread is earned by the liquidity provider. Price impact and realized spread are measured over a 5 -second horizon after the trade. High-speed trading proxies are: message traffic per volume in shares (MTVSh), message traffic per trade (MTTrd), cancellations per volume in shares (CANVSh), cancellations per trade (CANTrd), quote intensity per volume in shares (QIntVSh), and quote intensity per trade (QIntTrd). Message traffic is the total number LOB updates, which is equivalent to the sum of all order submissions, revisions, and cancellations. Quote intensity is measured by the number of quote or depth changes at the market quotes. As controls, we use the IBEX-35 volatility (Volat -1$)$, the IBEX-35 daily return (XRet-1), the first difference of the long-term Government debt yield of Spain ( $\triangle$ GBYield -1$)$, the first difference of the sovereign risk of Spain ( $\triangle$ SovRisk-1), measured as the spread between the long-term Government debt yield of Spain and Germany, and industrial sector dummies (not reported). All controls are lagged one period. The explanatory variable of interest is the dummy for the post-events period ("Post-Events"). 
TABLE 8

All events combined (Cont).

Panel A: Liquidity and trading activity

\begin{tabular}{|c|c|c|c|c|c|c|}
\hline Variable & $E S p r$ & Depth & LOBElast & $\mathrm{Vol}$ & Vol€ & Trades \\
\hline Cons. & $0.0923 * * *$ & $2170.815 * * *$ & $254.825 * * *$ & $411.935 * * *$ & $43.847 * * *$ & $23.958 * * *$ \\
\hline Post-Events & $0.0231 * * *$ & -84.830 & $-33.037 * * *$ & 66.286 & $-20.045 * *$ & $-4.016 * *$ \\
\hline Volat $_{-1}$ & $0.0056 * * *$ & $-138.053 * * *$ & $-11.723 * * *$ & 42.866 & $3.048 * * *$ & $2.025 * * *$ \\
\hline XRet $_{-1}$ & $-0.2561 * * *$ & 5362.601 & $281.859 * * *$ & -798.821 & -38.783 & $-34.972 *$ \\
\hline$\Delta$ GBYield $_{-1}$ & -0.0366 & -352.609 & 36.781 & -223.366 & $-23.874 * * *$ & -4.350 \\
\hline$\Delta$ SovRisk $_{-1}$ & $0.0003 * * *$ & 2.509 & $-0.169 * * *$ & 1.082 & 0.093 & 0.004 \\
\hline Obs. & 7005 & 7005 & 7005 & 7005 & 7005 & 7005 \\
\hline Adj.-R2 & 0.0362 & 0.0026 & 0.0265 & 0.0012 & 0.0158 & 0.0048 \\
\hline $\mathrm{F}$ & 52.24 & 5.93 & 39.31 & 2.47 & 22.54 & 7.34 \\
\hline \multicolumn{7}{|c|}{ Panel B: Volatility, price efficiency, realized spreads, and price impact } \\
\hline Variable & & RVolat & Corr & PrErr & RSpr5 & PrImp5 \\
\hline Cons. & & $0.0790 * * *$ & $0.0623 * * *$ & 0.0124 & $0.0477 * * *$ & $0.0361 * * *$ \\
\hline Post-Events & & 0.0016 & $0.0078 * * *$ & 0.0319 & -0.0036 & $0.0185 * * *$ \\
\hline Volat $_{-1}$ & & $0.0086 * * *$ & 0.0016 & 0.0092 & 0.0004 & $0.0048 * * *$ \\
\hline XRet $_{-1}$ & & $-0.2419 * *$ & 0.1363 & 1.9533 & -0.0212 & $-0.1577 * * *$ \\
\hline$\Delta$ GBYield $_{-1}$ & & $-0.0528 * *$ & $-0.0420 *$ & 0.7585 & 0.0143 & $-0.0290 * *$ \\
\hline$\Delta$ SovRisk $_{-1}$ & & $0.0003 * *$ & $0.0003 * *$ & -0.0054 & -0.0001 & $0.0002 *$ \\
\hline Obs. & & 7005 & 7005 & 7005 & 7005 & 7005 \\
\hline Adj.-R2 & & 0.0492 & 0.0072 & -0.0001 & 0.1071 & 0.2579 \\
\hline $\mathrm{F}$ & & 60.38 & 11.24 & 0.84 & 169.37 & 198.24 \\
\hline \multicolumn{7}{|c|}{ Panel C: High-speed trading } \\
\hline Variable & MTVSh & MTTrd & CANVSh & CANTrd & QIntVSh & QIntTrd \\
\hline Cons. & $0.0421 * * *$ & $20.095 * * *$ & $0.0148 * * *$ & $6.957 * * *$ & $0.0182 * * *$ & $8.614^{* * *}$ \\
\hline Post-Events & 0.0078 & 4.650 & $0.0050 * *$ & $2.985 *$ & 0.0031 & 1.315 \\
\hline Volat $_{-1}$ & -0.0002 & 0.210 & 0.0001 & 0.133 & 0.0002 & $0.203 *$ \\
\hline XRet $_{-1}$ & $-0.0752 * *$ & $-31.334 *$ & -0.0305 & -12.606 & $-0.0296 * * *$ & $-13.901 *$ \\
\hline$\Delta$ GBYield $_{-1}$ & 0.0168 & 8.686 & 0.0072 & 3.830 & 0.0008 & 0.237 \\
\hline$\Delta$ SovRisk $_{-1}$ & -0.0001 & -0.032 & 0.0001 & -0.013 & 0.0001 & 0.002 \\
\hline Obs. & 7005 & 7005 & 7005 & 7005 & 7005 & 7005 \\
\hline Adj.-R2 & 0.0033 & 0.0056 & 0.0093 & 0.0133 & 0.0029 & 0.0065 \\
\hline $\mathrm{F}$ & 5.73 & 9.52 & 14.23 & 21.58 & 5.06 & 11.20 \\
\hline
\end{tabular}

$* * *, * *, *$ indicates statis tically significant at the $1 \%, 5 \%$ and $10 \%$ level, respectively. 


\section{APPENDIX I \\ List of SSE-listed stocks}

We provide the ticker(s), company name, industry sector (according to BME), and subsample classifications: "BC" means Blue Chip; "ADR" means listed as an ADR in the NYSE; "1STB" means affected by the first short-sale ban.

\begin{tabular}{|c|c|c|c|c|}
\hline & Ticker & Company name & Sector & Classifications \\
\hline 1 & $\mathrm{ABE}$ & Abertis Infraestructuras & Consumer services & $\mathrm{BC}$ \\
\hline 2 & ABG & Abengoa & Basic materials, industry and construction & \\
\hline 3 & ACS & Actividades de Construcción y Servicios & Basic materials, industry and construction & \\
\hline 4 & ACX & Acerinox & Basic materials, industry and construction & \\
\hline 5 & AMS & Amadeus IT Holdings & Technology and telecomunications & \\
\hline 6 & ANA & Acciona & Basic materials, industry and construction & \\
\hline 7 & BBVA & Banco Bilbao Vizcaya Argentaria & Financial services & $\mathrm{BC}, \mathrm{ADR}, 1 \mathrm{STB}$ \\
\hline 8 & BKT & Bankinter & Financial services & 1STB \\
\hline 9 & BME & Bolsas y Mercados Españoles & Financial services & 1STB \\
\hline 10 & CABK-CRI & Caixabank & Financial services & 1STB \\
\hline 11 & DIA & Dis tribuidora Internacional de Alimentación & Consumer services & \\
\hline 12 & ELE & Endesa & Oil and Energy & \\
\hline 13 & ENG & Enagas & Oil and Energy & \\
\hline 14 & FCC & Fomento de Construcciones y Contratas & Basic materials, industry and construction & \\
\hline 15 & FER & Ferrovial & Basic materials, industry and construction & \\
\hline 16 & GAM & Gamesa Corporación Tecnológica & Basic materials, industry and construction & \\
\hline 17 & GAS & Gas Natural SDG & Oil and Energy & \\
\hline 18 & GRF & Grifols & Consumer goods & \\
\hline 19 & IAG & International Consolidated Airlines Group & Consumer services & \\
\hline 20 & IBE & Iberdrola & Oil and Energy & \\
\hline 21 & IDR & Indra Sistemas & Technology and telecomunications & \\
\hline 22 & ITX & Industria de Diseño Textil, Inditex & Consumer goods & $\mathrm{BC}$ \\
\hline 23 & JAZ & Jazztel & Technology and telecomunications & \\
\hline 24 & MAP & Mapfre & Financial services & $\mathrm{BC}, 1 \mathrm{STB}$ \\
\hline 25 & MTS & Acelormittal & Basic materials, industry and construction & \\
\hline 26 & OHL & Obrascon Huarte Lain & Basic materials, industry and construction & \\
\hline 27 & POP & Banco Popular Español & Financial services & 1STB \\
\hline 28 & REE & Red Eléctrica Corporación & Oil and Energy & \\
\hline 29 & REP & Repsol & Oil and Energy & $\mathrm{BC}, \mathrm{ADR}$ \\
\hline 30 & SAB & Banco de Sabadell & Financial services & 1STB \\
\hline 31 & SAN & Banco Santander & Financial services & $\mathrm{BC}, \mathrm{ADR}, 1 \mathrm{STB}$ \\
\hline 32 & SCYR-SYV & Sacyr & Basic materials, industry and construction & \\
\hline 33 & TEF & Telefónica & Technology and telecomunications & $\mathrm{BC}, \mathrm{ADR}$ \\
\hline 34 & TL5 & Mediaset España Comunicación & Consumer services & \\
\hline 35 & TRE & Técnicas Reunidas & Basic materials, industry and construction & \\
\hline 36 & VIS & Viscofan & Consumer goods & \\
\hline
\end{tabular}




\section{APPENDIX II \\ Short-sale bans: Comparative effect on market quality}

We evaluate the relative impact of the second short-sale ban (SSB2), which affects all stocks, from July 23, 2012 to November 11, 2012 (before colocation is introduced) to the effect of the first short-sale ban (SSB1), which affects only financial stocks (eight in our sample) from August 11, 2011 to February 15, 2012. We test for differences in liquidity and trading activity (Panel A), and volatility, price efficiency, realized spreads, and price impact (Panel B) in SSB2 versus SSB1. This table presents the estimated coefficients from pooled regressions with double-clustered standard errors. High-frequency data is aggregated to obtain daily statistics. Liquidity proxies are: effective spread weighted by trade size (x100) (ESpr); time-weighted quoted depth (Depth); and LOB elasticity (LOBElast). ESpr is an inverse measure while Depth and LOBElast are direct measures of liquidity. Market activity proxies are: the daily volume in shares ( $\mathrm{Vol})$ $\left(/ 10^{4}\right)$; the daily volume in euros $\left(\right.$ Vol€) $\left(/ 10^{6}\right)$, and the daily number of trades (Trades). Realized volatility (RVolat) is the daily standard deviation of 1-minute trade price returns (x100). Efficiency proxies are the autocorrelation of 1-minute trade price returns (Corr) and the pricing error standard deviation (PrErr), estimated using Hasbrouck (1993). Price impact (PrImp) measures the informativeness of trades (adverse selection cost), and the realized spread (RSpr) measures how much of the effective spread is earned by the liquidity provider. Price impact and realized spread are measured over a 5-second horizon after the trade. The explanatory variable of interest is the dummy for the second short-sale ban period ("SSB2"). As controls, we use the IBEX-35 volatility (Volat -1 ), the IBEX-35 daily return (XRet-1), the first difference of the long-term Government debt yield of Spain $\left(\triangle G B Y i e l d_{-1}\right)$, the first difference of the sovereign risk of Spain ( $\triangle$ SovRisk-1), measured as the spread between the long-term Government debt yield of Spain and Germany, and industrial sector dummies (not reported). All controls are lagged one period.

Panel A: Liquidity and Market activity

\begin{tabular}{|c|c|c|c|c|c|c|}
\hline Variable & ESpr & Depth & LOBElast & $\mathrm{Vol}$ & Vol€ & Trades \\
\hline Cons. & $0.1131 * * *$ & $1777.461 * * *$ & $191.664 * * *$ & $319.812 * * *$ & $29.897 * * *$ & $20.083 * * *$ \\
\hline SSB2 & $0.0636 * * *$ & $-416.521 * * *$ & $-35.779 * * *$ & $-64.658 *$ & $-13.600 * * *$ & $-6.969 * * *$ \\
\hline Volat $_{-1}$ & $0.0118 * * *$ & -34.877 & $-9.895 * * *$ & $45.050 * * *$ & $2.625 * * *$ & $1.743 * * *$ \\
\hline XRet $_{-1}$ & -0.0008 & $35.867 * *$ & $1.893 * * *$ & $-8.166 * * *$ & -0.310 & $-0.322 *$ \\
\hline$\Delta$ GBYield $_{-1}$ & 0.0055 & $-247.178 * * *$ & 6.581 & $-142.775 * * *$ & $-10.384 * * *$ & $-5.154 * * *$ \\
\hline$\Delta$ SovRisk $_{-1}$ & 0.0000 & -0.300 & -0.033 & 0.088 & 0.015 & 0.006 \\
\hline Obs. & 7169 & 7169 & 7169 & 7169 & 7169 & 7169 \\
\hline Adj.-R2 & 0.1094 & 0.0219 & 0.0545 & 0.0058 & 0.0145 & 0.0210 \\
\hline $\mathrm{F}$ & 132.51 & 46.52 & 83.13 & 5.92 & 23.22 & 29.78 \\
\hline \multicolumn{7}{|c|}{ Panel B: Volatility, efficiency, price impact, and realized spreads } \\
\hline Variable & & RVolat & Corr & PrErr & RSpr5 & PrImp5 \\
\hline Cons. & & $0.0829 * * *$ & $0.0637 * * *$ & $0.1143 * *$ & $0.0773 * * *$ & $0.0417 * * *$ \\
\hline SSB2 & & 0.0083 & $0.0101 * * *$ & $0.2192 * * *$ & $0.0230 * * *$ & $0.0172 * * *$ \\
\hline Volat $_{-1}$ & & $0.0169 * * *$ & 0.0008 & -0.0318 & 0.0013 & $0.0092 * * *$ \\
\hline XRet $_{-1}$ & & $-0.0029 * * *$ & 0.0002 & 0.0029 & $0.0010 * *$ & $-0.0021 * * *$ \\
\hline$\Delta$ GBYield $_{-1}$ & & -0.0213 & $-0.0131 *$ & 0.2015 & -0.0042 & -0.0015 \\
\hline$\Delta$ SovRisk $_{-1}$ & & 0.0001 & $0.0001 *$ & -0.0005 & 0.0001 & 0.0001 \\
\hline Obs. & & 7169 & 7169 & 7169 & 7169 & 7169 \\
\hline Adj.- $\mathrm{R}^{2}$ & & 0.1956 & 0.0080 & 0.0005 & 0.2431 & 0.2979 \\
\hline $\mathrm{F}$ & & 221.07 & 11.35 & 3.55 & 252.53 & 266.52 \\
\hline
\end{tabular}

$* * *, * *, *$ indicates statistically significant at the $1 \%, 5 \%$ and $10 \%$ level, respectively. 


\section{APPENDIX III \\ Short-sale bans: Comparative effect on realized volatility, price efficiency, realized spreads, and price impacts}

We evaluate the relative impact of the second short-sale ban (SSB2), which affects all stocks, from July 23, 2012 to November 11, 2012 (before colocation is introduced) to the effect of the first short-sale ban (SSB1), which affects only financial stocks (eight in our sample) from August 11, 2011 to February 15, 2012. We test for differences in high-speed trading in SSB2 versus SSB1. This table presents the estimated coefficients from pooled regressions with double-clustered standard errors. High-frequency data is aggregated to obtain daily statistics. HFT proxies are: message traffic per volume in shares (MTVSh), message traffic per trade (MTTrd), cancellations per volume in shares (CANVSh), cancellations per trade (CANTrd), quote intensity per volume in shares (QIntVSh), and quote intensity per trade (QIntTrd). Message traffic is the total number LOB updates, which is equivalent to the sum of all order submissions, revisions, and cancellations. Quote intensity is measured by the number of quote or depth changes at the market quotes. The explanatory variable of interest is the dummy for the second short-sale ban period ("SSB2"). As controls, we use the IBEX-35 volatility (Volat -1$)$, the IBEX-35 daily return (XRet $\left.{ }_{-1}\right)$, the first difference of the long-term Government debt yield of Spain ( $\triangle$ GBYield $\left.{ }_{-1}\right)$, the first difference of the sovereign risk of Spain ( $\triangle$ SovRisk $\left._{-}\right)$, measured as the spread between the long-term Government debt yield of Spain and Germany, and industrial sector dummies (not reported). All controls are lagged one period.

\begin{tabular}{|c|c|c|c|c|c|c|}
\hline$\overline{\text { Variable }}$ & MTVSh & MTTrd & CANVSh & CANTrd & QIntVSh & QIntTrd \\
\hline Cons. & $0.0538 * * *$ & $29.158 * * *$ & $0.0236 * * *$ & $12.879 * * *$ & $0.0240 * * *$ & $12.787 * * *$ \\
\hline SSB2 & $-0.0113 * * *$ & $-8.883 * * *$ & $-0.0072 * * *$ & $-4.928 * * *$ & 0.0008 & -0.928 \\
\hline Volat $_{-1}$ & 0.0002 & $0.955 * *$ & -0.0002 & 0.182 & 0.0001 & $0.427 * *$ \\
\hline XRet $_{-1}$ & $-0.0017 * * *$ & $-0.909 * * *$ & $-0.0005 * *$ & $-0.207 * *$ & $-0.0006 * *$ & $-0.245 * *$ \\
\hline$\Delta$ GBYield $_{-1}$ & -0.0031 & -0.509 & 0.0001 & 0.719 & -0.0002 & 1.049 \\
\hline$\Delta$ SovRisk $_{-1}$ & 0.0001 & 0.013 & 0.0001 & 0.003 & 0.0001 & 0.007 \\
\hline Obs. & 7169 & 7169 & 7169 & 7169 & 7169 & 7169 \\
\hline Adj.-R2 & 0.0082 & 0.0422 & 0.0149 & 0.0564 & 0.0009 & 0.0079 \\
\hline $\mathrm{F}$ & 13.43 & 58.93 & 25.56 & 92.95 & 2.80 & 12.74 \\
\hline
\end{tabular}

$* * *, * *, *$ indicates statistically significant at the $1 \%, 5 \%$ and $10 \%$ level, respectively. 